\title{
The analysis of customer satisfaction factors which influence chatbot acceptance in Indonesia
}

\author{
Lim Sanny $^{a^{*},}$ Ari Clementin Susastra ${ }^{a}$, Choky Roberts $^{\mathrm{a}}$ and Reflia Yusramdaleni $^{\mathrm{a}}$
}

${ }^{a}$ Business Management Program, Management Department, BINUS Business School Master Program, Bina Nusantara University, Jakarta, Indonesia 11480

\section{H R O N I C L E}

\section{Article history:}

Received: October 26, 2019

Received in revised format: No-

vember 212019

Accepted: November 25, 2019

Available online:

November 25, 2019

Keywords:

Chatbot

Customer Satisfaction

Customer Service

e-Service

Artificial Intelligence

\author{
A B S T R A C T \\ Chatbot program has evolved in the Indonesian market as the representative of online service customer that \\ provides immediate response and it is able to interact with customers by using Natural Language Processing. \\ This study aims to determine the extent of the customer satisfaction factors that successfully influence chatbot \\ acceptance in Indonesia. A sample of 119 respondents is chosen using Exploratory Factor Analysis method. \\ The findings deliver valuable insight of four factors in satisfying Indonesian customers when using Chatbot. \\ The research conclusion not only gives a new perspective to identify important factors influencing customer \\ satisfaction for chatbot acceptance in Indonesia but also helps Indonesian organizations look up at those factors \\ when planning to develop chatbot for their businesses.
}

(C) 2020 by the authors; licensee Growing Science, Canada

\section{Introduction}

"Chatbot" comprises of the expression of "talk" and "robot". The word "chatbot" consists of the term "chat" and "robot". Basically, it simulates human language with the help of natural language processing in a software program. Chatbots are accessible through mobile users to communicate and interact with a real individual (Wang \& Petrina, 2013). Chatbot also provides personalized support with the service quality that is always available to meet customer needs 24/7 (Chung et al., 2018). Chatbots are predicted to be dominant in the customer market by Gartner (2016) and they stated by 2020 , commonly people will have more conversations with bots than with their couple. Especially in the business industry, chatbots have positively impacting customer satisfaction through their abilities to improve the customer service provided by a business as they seem flexible to the time and thus, have the ability to offer customer needs anytime anywhere (Haan, 2018). The first chatbot platform in Indonesia according to Media Indonesia (2018) was introduced by Kata.ai. Kata.ai which was formed in 2016 with business model business to business (BTB) with the purpose of making people's lives easier through technology. The implementation of chatbot has been expanded and Indonesia's First Law Chatbot which aims to make people easily interact to ask questions about marital law, divorce law, and inheritance law (Hukum Online, 2018). While in the automotive industry in Indonesia, Auto2000 has launched TASIA, the first automotive chatbot in Indonesia, as a 24 hours virtual assistant customer (Auto2000, 2019). Moreover, most of large bank companies have developed chatbot as their customer service such as Bank BRI as Sabrina, Vira from Bank BCA, Bank BNI with Cinta and in the Telecommunication industry there are Veronika from Telkomsel, Maya from XL, and Indira from Indosat provider (Katadata.co.id, 2018). In fast-moving consumer goods (FMCG) industry there are only two chatbots which are Jemma from Unilever Indonesia and Shalma from Alfamart. Chatbots are expected to be able to give the customer better service experience when customers complain or asking information's (CNBC Indonesia, 2018). Ciechanowski et al. (2018) emphasized the attention to the factors that cause trust or

* Corresponding author. Tel.: +6221-7202222, Fax : +6221- 7205555

E-mail address: 1sanny@binus.edu (L. Sanny) 
resistance to technology innovations between human as the user of information technology in the professional environment by comparing how people interact with various chatbots that mimic human ways of interaction as well as human expertise (Ciechanowski et al., 2018). Budzikowska et al. (2001) found that a chatbot called 'Happy Assistant' in charge of helping users access e-commerce sites could find relevant information about products and services. They suggested that e-commerce sites with chatbot offer powerful personalized alternatives to traditional menu-driven or search-based interfaces to websites (Budzikowska et al., 2001). Other findings about the technological developments of chatbot have touched every aspect of human life that quantitative research analyzing factors influence technology acceptance of chatbot. Innovation, usefulness, and ease of use drive those millennials doing bank transactions with a chatbot (Richad et al., 2019).

In Customer Service, digital transformation has changed organization handed off more tasks to technology in a sustainable way (Otrs, 2018) especially chatbot that is able to proactively reaching the customer, providing availability for $24 / 7$, even reducing customer pain point in which they have serious effects on the customer satisfaction. Chatbot world varies to be studied starting from multiple point of view such as technological point of view, research on natural languages conversation of chatbot has been done by Shawar and Atwell (2007) concludes that chatbots is useful as a tool of entertainment, as a tool to learn and practice language as well as a tool to assist E-commerce, Business, and other domains (Shawar \& Atwell, 2007). Other studies on chatbot compared between the ability of common offline customer service agents in the marketing area and how to represent the brand and enhance customer/brand relationships (Lowry et al., 2009; Douglas \& Moore, 2009). Moreover, the findings obtained by Zumstein and Hundertmark (2017) from the perspective of organization indicate that chatbots could strongly influence and change the future of organizations, communications and collaborations within the companies.

From the customer satisfaction's perspective in journalism, obviously chatbots in the news media impact journalism and it allows the personalization of the information delivered and instant interaction among sources and respondents through trusting speech which includes giving emotion and loyalty (Gonzales \& González, 2017). Even from customer satisfaction's perspectives in healthcare, it shows a more recent example of a healthcare chatbot is Your.MD, which uses chatbot to provide patients with the most relevant health information and to connect them to check potential symptoms and to find safe health information even suggest patient to the right care professional (Your.MD, 2019). To conclude, chatbots provides efficient alternative solutions compared with traditional customer service in reducing human chat agents, or empowering the ability to respond various customers' needs (Mou \& Xu, 2017). Therefore, with the appealing use case of chatbot, the right requirements to develop chatbot may be the biggest contribution to satisfy customers' needs. According to the findings conducted by Lester et al. (2004), there are two sets of requirements to be effective for a chatbot implementation in an enterprise, natural language requirements (functional) and enterprise delivery requirements (Lester et al., 2004). Other studies about chatbot characteristics that motivates Portuguese Millennials using this software depends on Emotions, Personality, Conversational Abilities, Efficiency, Productivity, Entertainment, Social and Relational, Novelty and Curiosity (Rieke, 2018). In addition, Haan (2018) stated in his research that chatbots that have characteristic such as scalable, secure, reliable, and integrated without much effort and achieve high performances are the requirements that belong to large enterprises and yet their personality also impacts to the customer satisfaction as well. However, with the relevant theories and issues discussed above, the research in measuring chatbot requirements/factors toward customer satisfaction in Indonesia has not yet to be analyzed especially in Indonesia since potential of Chatbot business in Indonesia claims to be more promising. This issue is recognized as the gap between statement and findings of the previous studies performed in chatbot. Therefore, this research will present practical analysis on which factors may influence customer satisfaction toward chatbot applications, helping and showing to the relevant business industry or enterprises list of factors that generate customer satisfaction by using chatbot, so that it may help to develop chatbot application in satisfying their customers' needs or building customer relationship. The objective of this research is to analyze the factors of chatbot acceptance in Indonesia, identify customer preference in utilizing chatbot and to obtain understanding of customer satisfaction towards chatbot implementation in Indonesia.

\section{Literature review}

A chatbot is an artificial intelligence that uses Natural Language Processing (NLP) which makes chatbot capable of interpreting human language when there is a conversation with a human in text or voice format (Shawar \& Atwell, 2007). A chatbot usually refers to a computer program that has the ability to build a conversation with a human mostly through social media such as Facebook, WhatsApp or WeChat to give information as well as a platform to help audience doing the transaction that are not operated by the human but with the robots that has artificial intelligence ability to build the conversation (Zumstein \& Hundertmark, 2017) compared with the traditional loops of services provided by call center or email operated by the human customer service. Other research conducted by Xu et al. (2017) reveals that there are three measurement evaluations to assess respond quality for a chatbot in customer service such as Appropriateness, Empathy, and Helpfulness and there are two kinds of requests coming from customer which is Emotional Requests and Informational Requests. By implementing Deep Learning, a chatbot can have these three-measurement evaluations in order to respond the customers. The findings result that there was no statistically significant difference toward deep learning on chatbot and human agents on empathy for emotional requests. Deep Learning allows chatbot to paraphrase the conversation they had with customer for example, "I apologize for the poor user experience" to "I'm sorry you feel this way" since many organizations build their chatbot persona into an informal style so that the customers will have the same experience when in conversation with the human agent (Xu et al., 2017). Trust is considered as a social systemization and mutual character to lower transaction costs and promotes long-term customers 
relationships and triggers organization success (Freire, 2000). According to Herscovitch and Meyer (2002), organization might initiate positive emotional attachment level throughout different factors. Trust is the first factor and the relationship should have a greater positive value than perceived in other suppliers, and if these two works out well, the organization may have impact on positive emotional attachment to customers and this emotional response may keep long-term customer loyalty. Bricci et al. (2016) stated that there is a relationship between trust and commitment. Thus, it can be concluded that commitment is an important factor of loyalty for the responsible company to fulfill its commitments and perform the co-creation of value to its customers (Bricci et al., 2016). Other research on service quality, customer satisfaction, customer trust, and loyalty in an e-banking context argues that e-bank users have e-loyalty along with customer satisfaction and customer trust has strongly affected the e-service quality and their findings also provide insight (Chu et al., 2012). More specifically, trust in chatbot, findings conducted by Seeger and Heinzl (2018) about contingency factors of anthropomorphism as a trust stated that trustworthiness can be given by humanizing chatbot as if they are a real human agent when responding to customers queries (Seeger \& Heinzl, 2018). Perceived ease of use refers to having flexibility when an individual uses a software program (Davis, 1989). Meanwhile, others stated that perceived ease of use of any system could be more significant if the system perceived usefulness as well (Elkhani et al., 2014). Isaac et al. (2016) performed a study on the relationship between perceived ease of use, perceived compatibility, and net benefits on an empirical study of internet usage among employees in Yemen and found that perceived compatibility was the prior factor when users used a system. Other research conducted by Hussain et al. (2016) on perceived usefulness, perceived ease of use, and perceived enjoyment as drivers for the user acceptance of interactive mobile maps stated that users' acceptance of the interactive mobile maps was determined by three beliefs including perceived ease of use. Findings conducted by Richad et al. (2019) was about the factors that have positive impacts on millennial Indonesians upon accepting chatbot as a technology for the banking industry. They stated that excellent innovation is easy to be used like chatbot and showed the reasons those millennials in Indonesia accept chatbot in doing financial transactions with various bank in Indonesia.

Personality refers to individual characters and styles of thinking, feeling, and acting (Costa \& McCrea, 1995). According to the findings by Norman (1963), personality can be defined into five dimensions such as Extraversion or Surgency, Agreeableness, Conscientiousness, Emotional Stability, and Culture. But other research conducted by McCrea et al. (2005) argues that personality factors come from OCEAN: Openness, Conscientiousness, Extraversion, Agreeableness and Neuroticism. In short, there is an evidence that the personality of chatbot may attract customer satisfaction (Haan, 2018) for example Jemma personality allows customers ask variety of things, from fashion, to outpouring of relationships with lovers, horoscope and tips (Katadata.co.id, 2018).

A computer program is designed to interact with humans more when a computer program mimics a speaking person (Brandtzaeg \& Følstad, 2017). Findings about chatbot personality by Rieke (2018) stated that there are three emotions related to the interaction with chatbot: Happiness, Sadness, and Empathy (Rieke, 2018). Other research stated that humor is critical interaction from chatbot to users since it can serve to adjust the disagreements over the conversation, laughter can change conversation even in solving customers queries. Moreover, humor may avoid criticism and frustration over chatbot performance (Nijholt, 2003). To conclude, according to Cassell and Tartaro (2007) the purpose of the interaction between chatbot to users should not be aim to duplicate human but more to create interaction between a human and bots for specific customers' needs.

Natural Language Processing (NLP) allows chatbot to have knowledge in seeking information to customers and engage with them throughout conversation dialogs (Kerly et al., 2007; Lester et al., 2004; Shawar \& Atwell, 2007). Other research stated a framework of chatbot affects the design, therefore, affecting the knowledge base of the chatbot since the accuracy of the response of chatbot depends on the knowledge base (Abdul-Kader \& Woods, 2015). Interactive technology such as chatbot requires in-depth knowledge for users' motivations for using the technology (Brandtzaeg \& Følstad, 2017). In order to interact with customers, chatbots are utilized by fashion brand to provide timely answer, deliver wide and deep information to reduce uncertainty and provide customer satisfaction with accurate, credible and competent (Chung et al., 2018). Chatbots provides availability that can be accessed by customers $24 / 7$ without looking at common working hours (Zumstein \& Hundertmark, 2017). According to Rieke (2018), availability of chatbot means when other options of customer service is not offered from the business for a specific time duration, chatbot is able to provide automatic responses (Rieke, 2018). Other research conducted by Tezcan and Zhang (2014) stated that in customer service, requests through chat are going to be prioritized since chat is believed to be a more effective channel strategy than e-mail and telephone in handling multiple requests parallel with other customer service channel. The natural language of interaction between human whether its contextual or verbal is part of communication which studied further to search for new form of interaction between users and systems to exploits conversational approach with machine such as chatbot (Valtolina et al., 2018). Communication changes when people communicate with artificial intelligent such as chatbot. Although human language skills are easily translated to human-chatbot interaction, the content and quality of such conversation differ significantly. Despite all the limitation in imitating the intelligent of human conversation, many people are willing to have extensive interactions with chatbot (Hill et al., 2015). The study by Chung et al. (2018) reveals that the chatbot service provides immersive and engaging interaction between brand and customer service. It is shown that digital service assistance tools can allow positive brand on customer interaction (Chung et al., 2018). It was important to trust the brand that host the chatbot. A customer service chatbot is usually designed to support certain brand's customers and this brand's impression is one of the aspects to key trust determination. Through branding the chatbot, but also 
by accessing the chatbot from the product home page, brand was potentially affecting confidence of the chatbot users (Følstad et al., 2018). Chatbots need to be secure, reliable and interoperable with the existing (Følstad et al., 2018). Large enterprises only utilize chatbots that are scalable, secure and reliable without much effort and achieve high performance (Haan, 2018). Chatbot information is perceived as reliable as target users have expressed the findings as chatbot's understanding of accuracy is crucial to promote the usage of chatbot (Asher, 2017). Usefulness is one of dominant determinations of chatbot experiences on why people use chatbots (Brandtzaeg \& Følstad, 2017). The perception of the usefulness on utilizing chatbot comes from mobile phones users led to more positive attitudes among young customers towards mobile marketing as stated by Broeck et al. (2019). Online advertising literature indicates that an advertisement's perception of relevance is an important influence in advertising processing and plays an important role in generating cognitive, affective and behavioral outcomes. Chatbot advertising's perceived relevance moderate the mediation of message acceptance on the other factors of how chatbot can be accepted and effective for users (Broeck et al., 2019). Efficient service provision is the main determinant of consumer trust in customer service chatbots, as well as their probability of becoming regular users of chatbots. Users must consistently experience the chatbot channel as superior in performance (Følstad et al., 2018). The need of productivity and efficiency may be different in certain cultures and to understand the successful of chatbot and it is necessary for chatbot to be simple, quick and convenient such as receiving help or accessing information on the fly. Productivity is the main motivation for using chatbots as guarantee of efficient assistance (Brandtzaeg \& Følstad, 2017). Forty-two percent (42\%) of participated chatbot users stated ease of use, speed and convenience are their main reasons for using chatbots. The responses of the participants indicated that they were highly impressed when chatbots helped them save time or made it easier and quicker to access help or data, such as offering effective support in a customer-supported situation or pointing to an easy-to-use manual or frequent asked question (Brandtzaeg \& Følstad, 2017). The process interaction between chatbot and customer is still considered costintensive and time-intensive, which still seems a long way from becoming a good tool for customer cooperation (Filipczyk et al., 2016). Enjoyment or fun is important aspects of human social interaction. Entertainment and socialization are part of the aspects of human-chatbot relationship. Significant chatbot users commonly reported using chatbot for entertainment value \& how to pass time. It is also noteworthy that while chatbots can enhance human interactions, most users are sharing their chatbots experience socially. Chatbot is seen as a way of avoiding isolation or satisfying the need for socialization (Brandtzaeg \& Følstad, 2017).

\section{Methodology}

This research is investigating the factors which influence the chatbot acceptance in Indonesia that satisfy the customer as chatbot users. The methodology used in this research is Exploratory Factor analysis (EFA). This approach is chosen in order to lessen multiple data received to categorize the variable, define the relationship between the variables and the respondent. In addition, it's intended to also explain factors hypothetical background. The primary data received from questionnaire survey participated with the range of age between 17-40 years old. Participants were required to have previously interacted with chatbot and to have experience on what factors satisfy them while utilizing the chatbot. In the main study, the questionnaire comprised of 30 statements based on 5 points Likert scale were distributed through online, out of which 161 were received back. The sampling obtained total number of 119 samples and the rest of 42 were not included due to lack of experience in using chatbot and completing the answers. EFA refers to Exploratory Factor Analysis, it identifies structure factor or model for a set of variables (Bandalos, 1996). To process the collected data, there are two techniques for EFA which are Bartlett's test of sphericity (Bartlett, 1950; Dziuban \& Shirkey,1974) and the Kaiser-Meyer-Olkin (KMO) Measure of Sampling Adequacy (Dziuban \& Shirkey,1974; Kaiser,1970). Both of these methods are mandatory and have a correlation to perform EFA. Bartlett's test of sphericity is used to determine whether the observed correlation matrix is an identity matrix, which holds the property of having all off-askew estimations of zero (Tobias \& Carlson, 1969) while KMO Measure of Sampling Adequacies a pointer of regular change inside an informational index, which demonstrates that idle variables might be available and EFA might be performed (Dziuban \& Shirkey, 1974; Kaiser, 1970). In general, the results of Bartlett's test of sphericity and the KMO Measure of Sampling Adequacy are fundamentally the same as, yet the last gives different scopes of adequate fluctuation instead of just critical or nonsignificant. When the quantity of elements has been picked, the individual variable loadings should be deciphered; in any case, the underlying outcomes are hard to investigate. As referenced, numerous EFA strategies produce a legitimate factor framework that is easy to figure, however numerous other factor grids may likewise be right and simpler to decipher (Fabrigar \& Wegener, 2011). Thus, researchers must pivot their EFA arrangements. A few techniques exist, and these fall into two classifications: orthogonal and oblique.

\section{Results and discussion}

From Kaiser-Meyer-Olkin and Bartlett's Test, it can be seen that the amount of Kaiser-Meyer-Olkin is $0.910>0.5$, and also the amount of Bartlett's Test of Sphericity is 2776.780 with significant of $0.000<0,05$, meaning the $\mathrm{H}_{\mathrm{o}}$ is declined. So, the data is already qualified for further analysis. From the Measure of Sampling Adequacy Second Test all the indicators already met the criteria with amount $>0.5$, and can be concluded that the indicators are able to be proceeded to the next step. Factoring and Rotation Process for communalities all 30 indicators have extraction value $>0, .5$ that means all of the indicators are suitable for describing the factors formed.

With the criteria of Eigenvalues $>1$, there will be 4 factors formed:

1. Variance of 1 st factor is $16.405 / 30 \times 100 \%=54.685 \%$ 
2. Variance of 2 nd factor is $2.015 / 30 \times 100 \%=6.716 \%$

3. Variance of 3rd factor is $1.568 / 30 \times 100 \%=5.227 \%$

4. Variance of 4th factor is $1.185 / 30 \times 100 \%=3.991 \%$

So, the total of 4 factors will explain $70.578 \%$ of the origin 30 indicators.

Component Matrix shows the amount of correlation between a specific indicator to all the factors formed with the consideration in the case of the correlation is $>0.5$, it will be considered as a strong correlation with the factor formed. In the case of the correlation is $<0.5$, it will be considered as a weak correlation with the factor formed. In the case of the correlation is $>$ 0.5 but the value is minus (-), it will be considered as a strong correlation and the (-) sign only represents the direction of correlation.

Table 1

Component Matrix

\begin{tabular}{|c|c|c|c|c|}
\hline & \multicolumn{4}{|c|}{ Component } \\
\hline & 1 & 2 & 3 & 4 \\
\hline V20 & .876 & -.028 & -.198 & -.170 \\
\hline V21 & .825 & -.098 & -.175 & -.240 \\
\hline V15 & .823 & -.128 & -.095 & -.024 \\
\hline V28 & .822 & -.239 & .003 & -.085 \\
\hline V26 & .810 & .019 & .092 & -.164 \\
\hline V19 & .806 & -.023 & -.277 & -.146 \\
\hline V14 & .801 & -.010 & .070 & .116 \\
\hline V27 & .795 & -.153 & .172 & -.049 \\
\hline V8 & .790 & .057 & -.362 & .087 \\
\hline V9 & .788 & -.010 & -.311 & .088 \\
\hline V16 & .786 & -.042 & -.357 & .112 \\
\hline V29 & .772 & -.332 & .115 & .066 \\
\hline V24 & .769 & -.200 & .043 & -.262 \\
\hline V23 & .758 & -.194 & -.025 & -.146 \\
\hline V4 & .751 & .066 & -.238 & .292 \\
\hline V13 & .751 & -.287 & .149 & .090 \\
\hline V6 & .746 & .108 & -.437 & .097 \\
\hline V22 & .723 & .043 & .155 & -.205 \\
\hline V25 & .719 & -.215 & .020 & -.304 \\
\hline V7 & .695 & .148 & -.215 & .122 \\
\hline V30 & .694 & .086 & .430 & -.118 \\
\hline V17 & .669 & .427 & .208 & -.236 \\
\hline V5 & .663 & .260 & .106 & .312 \\
\hline V3 & .657 & .508 & .054 & -.015 \\
\hline V2 & .648 & .514 & .107 & .228 \\
\hline V10 & .646 & -.026 & .230 & .300 \\
\hline V18 & .642 & .380 & .319 & -.333 \\
\hline V11 & .627 & -.469 & .265 & .263 \\
\hline V1 & .613 & .509 & .168 & .218 \\
\hline V12 & .611 & -.378 & .391 & .339 \\
\hline
\end{tabular}

Extraction Method: Principal Component Analysis.

a. 4 components extracted.

From this finding, it can be concluded that with the criteria of Eigenvalues $>1$, there will be four factors formed. Factor 1 consists of nine variables such as Chatbot can help solve problems in a short time, Using Chatbot increases efficiency, The chatbot function is in line with my expectations, Chatbot provides comfort in terms of communication, Chatbot helps save my time, Chatbot is very useful and helpful, Chatbot provides convenience in solving problems, Chatbot answers according to questions, and Chatbot can be relied upon to solve problems, therefore all these variables can be included in factor 1; usefulness since Davis (1985) stated that among ten measurement of usefulness included that it can be categorized as usefulness if it can help to accomplish tasks immediately and useful for helping a job/task. The second factor consists of nine variables including My privacy security is guaranteed with chatbot, Chatbot can replace the role of company representative officer, I believe chatbot can solve problems, Chatbot delivers a good information, Communication with chatbots can be trusted, Chatbot is a representative of the company, Chatbot represents its brand well, Chatbot language can be understood very well, and Chatbot can answer all questions well, thus all these variables can be included in factor 2; Brand Image since the study by Chung et al. (2018) reveals that the chatbot service provides immersive and engaging interaction between brand and customer service. Its shown that digital service assistance tools can allow positive brand on customer interaction (Chung et al., 2018). The third factor consists of six variables including I chose chatbot with unique character/personality, Chatbot's character gives me a funny impression, Chatbot able to communicate like humans, Chatbot gives me a pleasant impression, Chatbot provides comfort in terms of friendliness, and Chatbot can interact well, hence all these variables can be included in factor 3; Personality since Personality refers to individual characters and styles of thinking, feeling, and acting (Costa \& McCrea, 1995). Last factor or the fourth factor consists of six variables which are Ease of accessing Chatbot, Ease of understanding the questions by chatbot, Communication with chatbot is easy to understand, I can access chatbot anytime, I can access chatbot from anywhere and Chatbot can provide a response in a short time, therefore all these variables can be included 
in factor 4; ease of use since Perceived ease of use refers to having flexibility when an individual uses a software program (Davis, 1989) meanwhile others wrote that perceived ease of use of any system will be more significant if the system perceived usefulness as well (Elkhani et al., 2014).

Table 2

Rotated component matrix will show a clearer variable distribution

\begin{tabular}{|c|c|c|c|c|}
\hline & & Con & 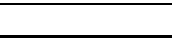 & 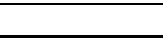 \\
\hline & 1 & 2 & 3 & 4 \\
\hline V6 & .797 & & & \\
\hline V8 & .762 & & & \\
\hline V16 & .761 & & & \\
\hline V9 & .721 & & & \\
\hline V4 & .685 & & & \\
\hline V19 & .656 & & & \\
\hline V20 & .630 & & & \\
\hline V7 & .598 & & & \\
\hline V15 & .549 & & & \\
\hline V25 & & .664 & & \\
\hline V24 & & .657 & & \\
\hline V21 & & .612 & & \\
\hline V26 & & .565 & & \\
\hline V22 & & .560 & & \\
\hline V23 & & .544 & & \\
\hline V28 & & .539 & & \\
\hline V30 & & .510 & & \\
\hline V27 & & .508 & & \\
\hline V12 & & & .846 & \\
\hline V11 & & & .805 & \\
\hline V29 & & & .624 & \\
\hline V13 & & & .617 & \\
\hline V10 & & & .568 & \\
\hline V14 & & & .461 & \\
\hline V1 & & & & .774 \\
\hline V2 & & & & .773 \\
\hline V3 & & & & .713 \\
\hline V17 & & & & .672 \\
\hline V18 & & & & .647 \\
\hline V5 & & & & .588 \\
\hline
\end{tabular}

\section{Conclusion}

Overall there are four customer satisfaction factors such as usefulness, brand image, personality, and ease of use that influence chatbot acceptance in Indonesia. All these four factors are believed to have correlation that can satisfy customers when using chatbot for Indonesian customers in which they can help organizations look up at these four factors when planning to develop chatbot in Indonesian market.

\section{References}

Asher, N. (2017). A warmer welcome: Application of a chatbot as a facilitator for new hires onboarding. Thesis, Social Media and Web Technologies, Linnaeus University.

Auto2000. (2019, February 14). AUTO2000 MEMPERKENALKAN TASIA, CHATBOT OTOMOTIF PERTAMA DI INDONESIA, SEBAGAI VIRTUAL ASSISTANT PELANGGAN 24 JAM. Retrieved October 13, 2019, from Auto2000: https:/auto2000.co.id/rilis/auto2000-memperkenalkan-tasia-chatbot-otomotif-pertama-di-indonesia-sebagai-virtual-assistant-pelanggan-24-jam/.

Freire, A. (2000). Inovação - Novos produtos, serviços, serviços e negócios para Portugal. Lisboa: Verbo.

Abdul-Kader, S. A., \& Woods, D. (2015). Survey on chatbot design techniques in speech conservation systems. International Journal of Advanced Computer Science and Applications, 6(7), 72-80.

Bandalos, D. L. (1996). Confirmatory factor analysis. J. Stevens (Ed.), Applied Multivariate Statistics for the Behavioral Sciences (2nd and 3rd ed., pp. 362-427). New Jersey: Lawrence Erlbaum Associates.

Bartlett, M. S. (1950). Tests of significance in factor analysis. British Journal of Psychology, 3, 77-85.

Brandtzaeg, P. B., \& Følstad, A. (2017). Why People Use Chatbots. The Proceedings of the 4th International Conference on Internet Science (pp. 377-392). Thessaloniki: Spinger.

Bricci, L., Fragata, A., \& Antunes, J. (2016). The Effects of Trust, Commitment and Satisfaction on Customer Loyalty in the Distribution Sector. Journal of Economics, Business and Management, 4(2), 173-177. 
Budzikowska, M., Chai, J., Govindappa, S., Horvath, V., Kambhatla, N., Nicolov, N., \& Zadrozny, W. (2001). Conversational sales assistant for online shopping. Proceedings of the First International Conference on Human Language Technology Research (pp. 1-2). New York: IBM T. J. Watson Research Center.

Cassell, J., \& Tartaro, A. (2007). Intersubjectivity in Human-Agent Interaction. Interaction Studies, 8, 391-410.

Chu, P. Y., Lee, G. Y., \& Chao, Y. (2012). Service quality, customer satisfaction, customer trust, and loyalty in an e-banking context. Social Behavior and Personality: An International Journal, 40(8), 1271-1283.

Chung, M., Ko, E., Joung, H., \& Kim, S. J., (2018). Chatbot e-service and customer satisfaction regarding luxury brands. Journal of Business Research, 1-9.

Ciechanowski, L., Przegalinska, A., Magnuski, M., \& Gloor, P. (2018). In the shades of the uncanny valley: An experimental study of human-chatbot interaction. Future Generation Computer Systems, 92, 539-548.

CNBC Indonesia. (2018, April 3). Ini Robot Bank di Indonesia: Cinta, Mita, Vira, dan Sabrina. Retrieved October 13, 2019, from CBNC Indonesia: https://www.cnbcindonesia.com/market/20180403112007-17-9463/ini-robot-bank-di-indonesiacinta-mita-vira-dan-sabrina.

Costa, Jr. P. T., \& McCrea, R. R. (1995). Domains and facets: Hierarchical personality assessment using the revised NEO personality inventory. Journal Of Personality Assessment, 64(1), 21-50.

Davis, F. D. (1985). A technology acceptance model for empirically testing new end-user information systems: Theory and results. Unpublished doctoral dissertation, The Sloan School of Management, Massachusetts Institute of Technology Commitment.

Davis, F. D. (1989). Perceived usefulness, perceived ease of use, and user acceptance of information technology. MIS Quarterly, 13(3), 319-340.

Douglas, A. F., \& Moore, C. M. (2009). The anatomy of the luxury fashion brand. Journal of Brand Management, 16(5), $347-$ 363.

Dziuban, C. D., \& Shirkey, E. C. (1974). On the psychometric assessment of correlation matrices. American Educational Research Journal, 11(2), 211-216.

Elkhani, N., Soltani, S., \& Ahmad, M. N. (2014). The effects of transformational leadership and ERP system self-efficacy on ERP system usage. Journal of Enterprise Information Management, 27(6), 759-785.

Fabrigar, L. R., \& Wegener, D. T. (2011). Introductory Factor Analysis Concepts. Exploratory Factor Analysis (pp. 1-18). Oxford Scholarship Online.

Filipczyk, B., Goluchowski, J., Paliszkiewicz, J., \& Janas, A., (2016). Success and failure in improvement of knowledge delivery to customers using chatbot - result of case study in a polish SME. Successes and Failures of Knowledge Management (pp. 175-189). Massachusetts: Elsevier.

Følstad, A., Nordheim, C. B., \& Bjørkli, C. A. (2018). What Makes Users Trust a Chatbot for Customer Service? An Exploratory Interview Study. The 5th International Conference of Internet Science (pp. 194-208). St. Petersburg: Spinger.

Gartner. (2016). Gartner Summit. Retrieved October 13, 2019, from Gartner: https://www.gartner.com/hukimagesrv/summits/docs/na/customer-360/C360_2011_brochure_FINAL.pdf

Haan, D. H., (2018). Chatbot Personality and Customer Satisfaction. Bachelor Thesis, Information Science, Utrecht University.

Hill, J., Ford, W. R., \& Farreras, I. G. (2015). Real Conversations with Artificial Intelligence: A Comparison between Humanhuman Online Conversations and human-chatbot conversations. Computers in Human Behavior, 49, 245-250.

Hussain, A., Mkpojiogu, E. O. C., \& Yusof, M. M. (2016). Perceived usefulness, perceived ease of use, and perceived enjoyment as drivers for the user acceptance of interactive mobile maps. AIP Conference Proceedings (pp. 1-6). New York: AIP Publishing.

Isaac, O., Abdullah, Z., Ramayah, T., \& Mutahar, A. M. (2016). Factors determining user satisfaction of internet usage among public sector employees in Yemen. International Journal of Technological Learning, Innovation and Development, 10(1), 37-68.

Herscovitch, L., \& Meyer, J. P. (2002). Commitment organization change: Extension of a three -component model of occupational commitment. Journal of Applied Psychology, 87(3), 474-487.

Kaiser, H. F. (1970). A second generation little jiffy. Psychometrika, 35(4), 401-415.

Katadata.co.id. (2018, June 14). Kata.ai, Startup Di Balik Layanan Chatbot Veronika dan Sabrina. Retrieved October 14, 2019, from katadata.co.id: https://katadata.co.id/berita/2018/06/14/kataai-startup-di-balik-layanan-chatbot-veronika-dansabrina.

Kata.ai. (n.d.). About Jemma Unilever. Retrieved October 6, 2019, from kata.ai: https://kata.ai/story/jemma.

Katadata.co.id. (2018, July 25). Telkomsel dan Indosat Bersaing Kembangkan Internet of Things. Retrieved October 14, 2019, from Katadata.co.id: https://katadata.co.id/berita/2018/07/25/telkomsel-dan-indosat-bersaing-kembangkan-internet-ofthings.

Kerly, A., Hall, P., \& Bull, S. (2007). Bringing chatbots into education: Towards natural language negotiation of open learner models. Knowledge-Based Systems, 20(2), 177-185.

Lester, J., Branting, K., \& Mott, B. (2004). Conversational agents. M. P. Singh (Ed.), The Practical Handbook of Internet Computing (1st ed., pp. 220-240). New York: Chapman \& Hall.

Lowry, P. B., Romano, N. C., Jenkins, J. L., \& Guthrie, R. W. (2009). The CMC Interactivity Model: How Interactivity Enhances Communication Quality and Process Satisfaction in Lean-Media Groups. Journal of Management Information Systems, 26(1), 155-195. 
McCrae, R. R., Costa, Jr, P. T., \& Martin, T. A. (2005). The NEO-PI-3: A more readable revised NEO personality inventory. Journal of Personality Assessment, 84(3), 261-270.

Mou, Y., \& Xu, K. (2017). The media inequality: Comparing the initial human-human and human-AI social interactions. Computers in Human Behavior, 72, 432-440.

Nijholt, A. (2003). Humour and Embodied Conversational Agents. (CTIT Technical reports series; No. 2003-03). Enschede: Centre for Telematics and Information Technology.

Norman, W. T. (1963). Toward an adequate taxonomy of personality attributes: Replicated factor structure in peer nomination personality ratings. The Journal of Abnormal and Social Psychology, 66(6), 574-583.

Otrs. (2018, November 12). The Impact of Digital Transformation on Customer Service Teams. Retrieved August 10, 2019, from OTRS: https://otrs.com/otrsmag/the-impact-of-digital-transformation-on-customer-service-teams/

Richad, R., Vivensius, G., Sfenrianto, S., \& Kaburuan, E. R. (2019). Analysis of factors influencing millennial's technology acceptance of chatbot in banking industry in Indonesia. International Journal of Civil Engineering and Technology, 10(4), 1270-1281.

Rieke, T. D. (2018). The relationship between motives for using a Chatbot and satisfaction with Chatbot characteristics in the Portuguese Millennial population: an exploratory study. Thesis. Faculty of Economics. University of Porto.

Gonzales, H. M. S., \& González, M. S. (2017). Bots as a news service and its emotional connections to audiences: The case of Politibot. Doxa Comunicación: Revista interdisciplinar de estudios de Comunicación y Ciencias Sociales, 25, 51-68.

Seeger, A. M., \& Heinzl, A. (2018). Human Versus Machine: Contingency Factors of Anthropomorphism as a Trust-Inducing Design Strategy for Conversational Agents. Information Systems and Neuroscience (pp. 129-139). New York: Springer.

Shawar, B. A., \& Atwell, E. (2007, January). Chatbots: are they really useful?. In Ldv forum (Vol. 22, No. 1, pp. 29-49).

Tezcan, T., \& Zhang, J. (2014). Routing and staffing in customer service chat systems with impatient customers. Operations Research, 62(4), 943-956.

Tobias, S., \& Carlson, J. E. (1969). Brief report: Bartlett's test of sphericity and chance findings in factor analysis. Multivariate Behavioral Research, 4(3), 375-377.

Wang, Y. F., \& Petrina, S. (2013). Using learning analytics to understand the design of an intelligent language tutor. International Journal of Advanced Computer Science \& Applications, 4(11), 124-131.

Valtolina, S., Barricelli, B. R., \& Gaetano, S. D. (2018) Chatbots and conversational interfaces: Three domains of use. Proceeding of Fifth International Workshop on Cultures of Participation in the Digital Age - CoPDA 2018 (pp. 62-70). Castiglione della Pescaia: CEUR Workshop Proceedings.

Broeck, E. V. D., Zarouli, B., \& Poels, K. (2019). Chatbot Advertising Effectiveness: When Does the Message Get Through? Computers in Human Behavior, 98, 150-157.

Xu, A., Liu, Z., Guo, Y., Sinha, V., \& Akkiraju, R. (2017). A New Chatbot for Customer Service on Social Media. CHI Conference (pp.3-4). Colorado: IBM Research - Almaden.

Your.MD. (n.d.). Our mission is simple: to help you find your health. Retrieved October 14, 2019, from Your.MD: https://www.your.md/about/

Zumstein, D., \& Hundertmark, S. (2017). Chatbots-An interactive technology for personalized communication, transactions and services. IADIS International Journal on WWW/Internet, 15(1), 96-109.

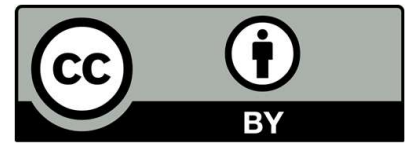

(C) 2020 by the authors; licensee Growing Science, Canada. This is an open access article distributed under the terms and conditions of the Creative Commons Attribution (CC-BY) license (http://creativecommons.org/licenses/by/4.0/). 